\title{
Exploratory Study of Adolescents' Representations of the Congolese Lushoise Family: Stories and Typical Profiles
}

\author{
Marthe KABWE KABELA KANKUMBA
}

PhD Student in Clinical Psychology at the University of Lubumbashi: markabkan[at]yahoo.fr, 243814003642

\begin{abstract}
The main objective of this article is to present the results of an exploratory study of our ongoing doctoral research, which prepares research on emotional disorders in adolescence related to family experiences. This research has been more motivated by the mental health of adolescents in a society that is transforming like ours. The aim was above all to sketch the different typical profiles of the Congolese Lushoise family made by teenagers starting from the stories, whose age varies between 12 and 17 years, but also to determine the element able to typologize this starting representation. of a speech. To make it concrete, a qualitative and quantitative study was made on the speeches produced by 70 randomly selected young people in the city of Lubumbashi. Their statements were processed using non-computer-assisted thematic analysis. It emerges from this preliminary study, that the family history or the story of family life determines the representation of the family universe, and representations of Congolese teenagers Lush. In a second step, our doctoral research will focus on the research of the most decisive factors in the emergence of emotional disorders (sociological or historical criteria). The results of this first study allowed us to identify four typical family profiles, referring to the influence of family history of adolescents. These are Positive Internal Events, Internal Negative Events, Positive External Events, and Negative External Events.
\end{abstract}

Keywords: Representations - family - adolescents - history

\section{Introduction}

This article follows several studies on the emotional disorders of adolescents, most of which focus on the family on the one hand and adolescents on the other, a stage of life which is an essential element in psychological development and which is at the center of our thinking.

The representations we give of the world around us, occupy an important place in psychology, as in other disciplines (Ferréol, Cauche, Duprez, Gadrey and Simon, 1991), by the simple fact that they are at the base our motivation; they manifest the basis of our spontaneous epistemology and are rooted in the heart of this social device (Mannoni, 2012), called the family, which is a subject of much attention (Delage, 2008). The latter plays an essential role in the construction of identity and conditions our behavior (Moscovici, 1984). On the other hand, Duret and Lefebvre (1997: 55) argue that: "Adolescence is a key period, as we know, for the construction of identity. It is a stage in the development of an individual but it is an integral part of the evolution of any family. It is within the family that the adolescent will first seek to question his sense of self. Rassial (2009) confirms that the identity of the adolescent is reflected in his speech or in pathology. In other words, young people who are going through adolescence are fragile and able to develop a certain number of pathologies due to the disruption of identity, and this can be seen through the discourse they produce. It turns out that the construction of identity depends on the meeting of two important elements, adolescence and family. This is sometimes violently challenged by young people and that is why, Duret and Lefebvre (1997) conclude that the family sees its story jostled by the teenager. But to ensure proper adolescent development, families must themselves resist these violent attacks. The meeting of these two determinants is part of a temporal development that constitutes the family history that shapes the representations of the young adolescent. Because of this, knowledge of the typical family profiles is an element of great importance for the therapist when taking care of patients.

It is therefore a question if we want to know better these representations of plunging us into these stories, each time particular. But scientific research requires generalizations and cannot be satisfied with singularities. This is the reason why we have chosen to carry out a qualitative research at first by giving free rein to the teenagers' discourse and then trying to group these remarks in thematic generalizations.

Nowadays, the family is an institution that knows a real change (Sylvie, 2011). In the city of Lubumbashi, as in the other cities of the province of Upper Katanga, families undergo social transformations of many kinds and orders. This is due to socio-economic-political realities, which can be associated with natural disasters. By this we mean the mixing of cultures following modernization and the phenomenon of urbanization, the proliferation of mining companies with a considerable impact on the wage income of agents. This favors the completion of work hundreds of kilometers away. The homogenization of cultures is causing families to lose their values and their benchmarks (Bizige, 2012). To this can also be added a current phenomenon, that of territorial division. This phenomenon favors tribalism because the wish of each province is to promote its native people. This reality has an impact both politically and socially. We find that some families find themselves trapped in politics, and suffer adverse consequences. This is more noticeable in families where spouses do not all have the same province of origin. There is then a problem that children suffer, that of belonging,

\section{Volume 6 Issue 12, December 2017}




\section{International Journal of Science and Research (IJSR) \\ ISSN (Online): 2319-7064}

Index Copernicus Value (2016): 79.57 | Impact Factor (2015): 6.391

and these become victims and taken hostage by this phenomenon. All these realities mean that in one way or the other, the Congolese family in Lushoise is weakened and generates various images of his universe close to these members, and specifically beings in continuous growth. Thus, knowledge of family representations can be of considerable importance if, on the other hand, one wishes to develop prevention policies for certain disorders (Castillo, Lannoy, Seznec, Januel and Petitjean, 2007), particularly emotional and behavioral disorders.

It should be noted that an important study was carried out by Pauzé, Déry, Yergeau and Touchette (2005) whose main objective was to identify the different typical family profiles in children with externalized and internalized behavioral disorders. Through interviews and questionnaires on family and behavioral characteristics. They identified four distinct patterns that are characterized by the following: 1) Attention Deficit Hyperactivity Disorder (ADHD); 2) an antisocial disorder; 3) ADHD and antisocial disorder and 4) insufficient number of symptoms to reach the diagnostic thresholds for any of these conditions. It follows from the above that the categorization of the standard profiles (which are four in number) elaborated by Pauzé et al. only applies to children with behavioral problems who are already receiving specialized educational services for this type of difficulty in primary school. They are based on maladjustment, which is reflected in academic delay, and the nature of the disorder (externalized or internalized). On the other hand, the categorization of our typical profiles (which are also four in number) applies to all adolescents, without first taking into account their morbid states, and is based on the discourse produced by the subjects surveyed on their subjects own families.

Through this exploratory study, we ask ourselves the following questions:

a) What would be the element able to typologize the representation of the Congolese family by young Lushois teenagers starting from the discourse?

b) What would be the typical profiles of the Congolese family?

The results obtained during this study will guide the final goal of our current doctoral research, which aims to uncover the link between the representations that adolescents make of their families and the emergence of emotional disorders. This will be possible following a series of three separate studies following this one, which constitute our doctoral research, strictly speaking.

The first will allow us to verify and refine the results obtained in this exploratory study, this time on a large and representative sample of adolescents.

In the second, it will be a question of determining the narrative elements salient in the speeches of the normal teenagers, depressive and anxious. Then, identify the different themes that emerge in the various narratives of life stories of the family of young people. And finally, look for external determinants that influence pathology (emotional disorders).

The last study will detect the elements that are related to emotional disorders and the representation of the family (unconscious representations of the family, family history,), close to young adolescents anxious and depressed. It will also determine the paradigm of emergence of depression and anxiety near the young, hence the predominant element.

\section{Methodology}

We extracted the sample empirically in the city of Lubumbashi. The technique that seemed appropriate to us, is quota sampling, also called directed or by reasoned choice. Ardilly P. (1994), Legras and Kohler (2007) consider that this technique is well suited and widely used for opinion surveys and market studies. As part of this exploratory study, this sampling technique made it possible to extract a group of young people from different groups based on geographic area, age, sex and grade level, while respecting the quota. that we had assigned ourselves from the beginning for this exploratory study.

It is composed of 70 adolescents ( 35 girls and 35 boys) aged 12 to 17 years (average age $=15$ years), from the Democratic Republic of Congo, in the province of Upper Katanga, precisely in the city of Lubumbashi. It is divided into three age categories, namely 12 to 13 years, ie 10 adolescents; 14 to 15 years, 27 children and 16 to 17 years, or 33 adolescents.

In concrete terms, a 12-question interview guide was produced which allowed for the first collection of data. The transcription of the verbatim of 6 young people, including 3 boys and 3 girls, who took part in the first pretest, detected very stereotypical answers, with the aim of improving the questionnaire, hence an improvement of this first version. The second version had 13 questions and was administered to four young people, including 2 girls and 2 boys. The observations made after the transcript led to the development of a coherent and elaborate, definitive, 14item guide that was used to gather opinions from the adolescents involved in this study.

The verbatim collected in this study provided the data that was analyzed by thematic analysis, which Negura (2006) considers to be an integral part of the content analysis method, whose purpose is to is to identify the semantic fundamental elements (identification of significant ideas) by grouping them within the categories (categorization). The use of this method is justified by the fact that the data collection questionnaire used in this study contained several pieces of information, namely elements related to social status, economic dimension, ethical origin, and than religious beliefs. This is why this method allowed us to identify the most important determinants. We present in Appendix 1 the final version of the interview guide.

Apart from this method, we also made use of the statistical method which allowed us to perform a descriptive analysis 


\section{International Journal of Science and Research (IJSR) \\ ISSN (Online): 2319-7064}

Index Copernicus Value (2016): 79.57 | Impact Factor (2015): 6.391

of the data in order to determine the different percentages whose purpose is to make comparisons.

\section{Results}

The results from the qualitative and quantitative analyzes reveal the following:

The representation of the Congolese family of Lushoises those adolescents make depends mainly on family history rather than ethnic or religious origins. In other words, it is the past lived of the adolescent in his family that dominates his representations. Thus, we dare to conclude at this level that the story of the family or the life story of the young adolescent is the central element of any representation of the family, which we consider the "central core". It is built on the past, the present, and projects into the future.

Starting from the family histories collected, we found a great coherence in the different stories produced by the teenagers, which allowed us to identify the different themes, by a non-computer-assisted thematic analysis. These themes were grouped together taking into account the way in which the stories began and ended in the same general representation. This allowed a generalization and categorization in a distinct way, taking into account the events around which the family history was organized. It turns out that teenagers' discourses are dominated by two types of essential events, namely: internal and external events. Then we combined valence with each of two events: either an attraction (positive or happy event) or a repulsion (negative or unfortunate events). At the end of this growth, it turns out that teenagers' speeches are categorized into four types of typical profiles, namely: families that are influenced by positive internal events (IPE), negative internal events (IPE) positive external events (PEE) and negative external events (PEE).

Table 1: Staff presentation according to events and valence

\begin{tabular}{|c|c|c|c|c|}
\hline $\begin{array}{c}\text { Exents } \\
\text { Valenee }\end{array}$ & Internal & External & Total & \% \\
\hline Positive & 25 & 13 & 38 & 54,29 \\
\hline Negative & 19 & 13 & 32 & 45,71 \\
\hline Total & 44 & 26 & 70 & 100,00 \\
\hline \% & 62,86 & 37,14 & 100,00 & \\
\hline
\end{tabular}

This table presents the numbers and percentages of the different typical profiles of the family that have characterized the family narratives of Congolese Lushois adolescents. It shows that most speeches contain internal events, and this represents $62.86 \%$. External events represent $37.14 \%$. The valence of events is more positive at $54.29 \%$, and the negative valence is $45.71 \%$. As a result, the way in which the Congolese Lushois teenagers are told has a significant difference both in the forms of events (Internal: $62.86 \%$ and external: $37.14 \%$ ) than in the valence of events (Positive: 54.29 \% and Negative: $45.71 \%$ ). To give meaning to the different figures, we realize that divorce, misunderstanding, irresponsibility of parents, polygamy, infidelity between spouses, abandonment of children by parents, relationship difficulties between members (lack of harmony, happiness, good attitudes between members,...), feelings of contempt, jealousy, remarkable spirit of cohesion between members, a strong working spirit and close collaboration, the Mysterious deaths (witchcraft) are factors that have been more indexed and that justify the fact that many teens are telling each other more internally.

The difficult conditions of material or financial order, the lack of employment by one of the parents, much more the father, the low remuneration, the behavior influenced by a third person (driving of drunkenness, moving movement,...), the case of natural death, catastrophes of all kinds: war, flood, fire, accident, etc. are key factors that have been identified and that justify external events.

Subsequently, we also asked ourselves whether family history produced by a teenager alone was enough to determine a teenager's portrayal of his family. From the analysis made, it appears that it is influenced by several other factors, on the one hand causal situations and on the other hand variables. Thus, that the representation that a teenager is made is his family is firstly influenced by the history of his family. This story is a function, on the one hand, of causal situations, such as divorce, death, lack of employment, work, family cohesion, etc. And, on the other hand, variables in presence (sex, age, level of study of the mother, profession of the mother...). Variables can be distinguished into two categories: those that are directly related and those that are indirectly related (see Figures 1, 2,3 and 4). The causal situation plays a primordial role in the construction of the narrative, to better say generates and directs the very essence of the story or story. On the other hand, directly related variables such as: sex, religion, age, family system, sibling position, and mother's education level, are factors that, at first glance, analysis allowed teens to vary their stories.

The latter have already been established by other research (Boulard 2012, Erikson, 1968) as variables capable of influencing a phenomenon, as is the case for directly related variables. This reality can be presented in a figure below:

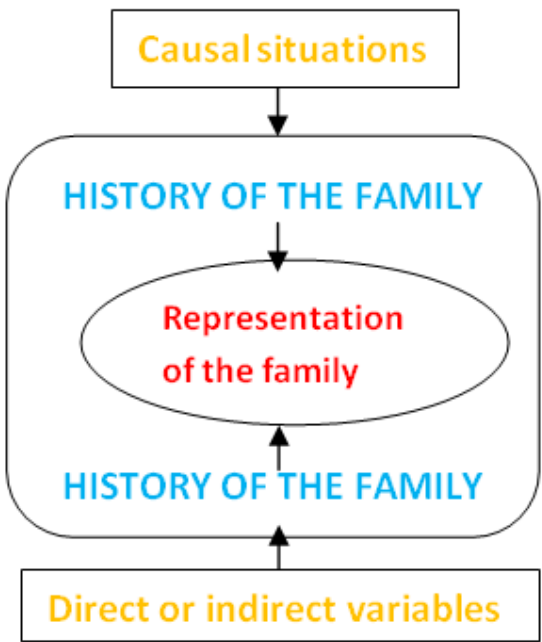

Figure 1: Mechanism of emergence of a representation of the family

Source: Our own production.

\section{Volume 6 Issue 12, December 2017}




\section{International Journal of Science and Research (IJSR) \\ ISSN (Online): 2319-7064}

Index Copernicus Value (2016): 79.57 | Impact Factor (2015): 6.391

Table 2: Presentation of enrollments by profile and sex

\begin{tabular}{|l|l|l|l|l|}
\hline $\begin{array}{l}\text { Sex } \\
\text { Type Profiles }\end{array}$ & girl & boy & Total & \% \\
\hline EEP & 6 & 7 & 13 & 18,57 \\
\hline EEN & 6 & 7 & 13 & 18,57 \\
\hline EIP & 12 & 13 & 25 & 35,72 \\
\hline EIN & 11 & 8 & 19 & 27,14 \\
\hline Total & 35 & 35 & 70 & 100,00 \\
\hline \% & 50 & 50 & 100 & \\
\hline
\end{tabular}

In this table, we present the way in which sex is distributed through different types of profiles. Girls tell each other more internally ( 23 out of 44 ) compared to boys ( 21 out of $44)$. On the other hand, boys report more externally (14 out of 26) compared to girls (12 out of 26). This presentation allows us to hypothesize how to tell each other based on the sex variable.

Based on these results, we can ask ourselves the question of whether girls actually tell more stories internally than boys?

We could not make a remarkable comparison with the age variable, as the distribution across age groups is not equitable. However, we realized that the speeches regardless of the different age groups presented coherence with regard to the different topics.

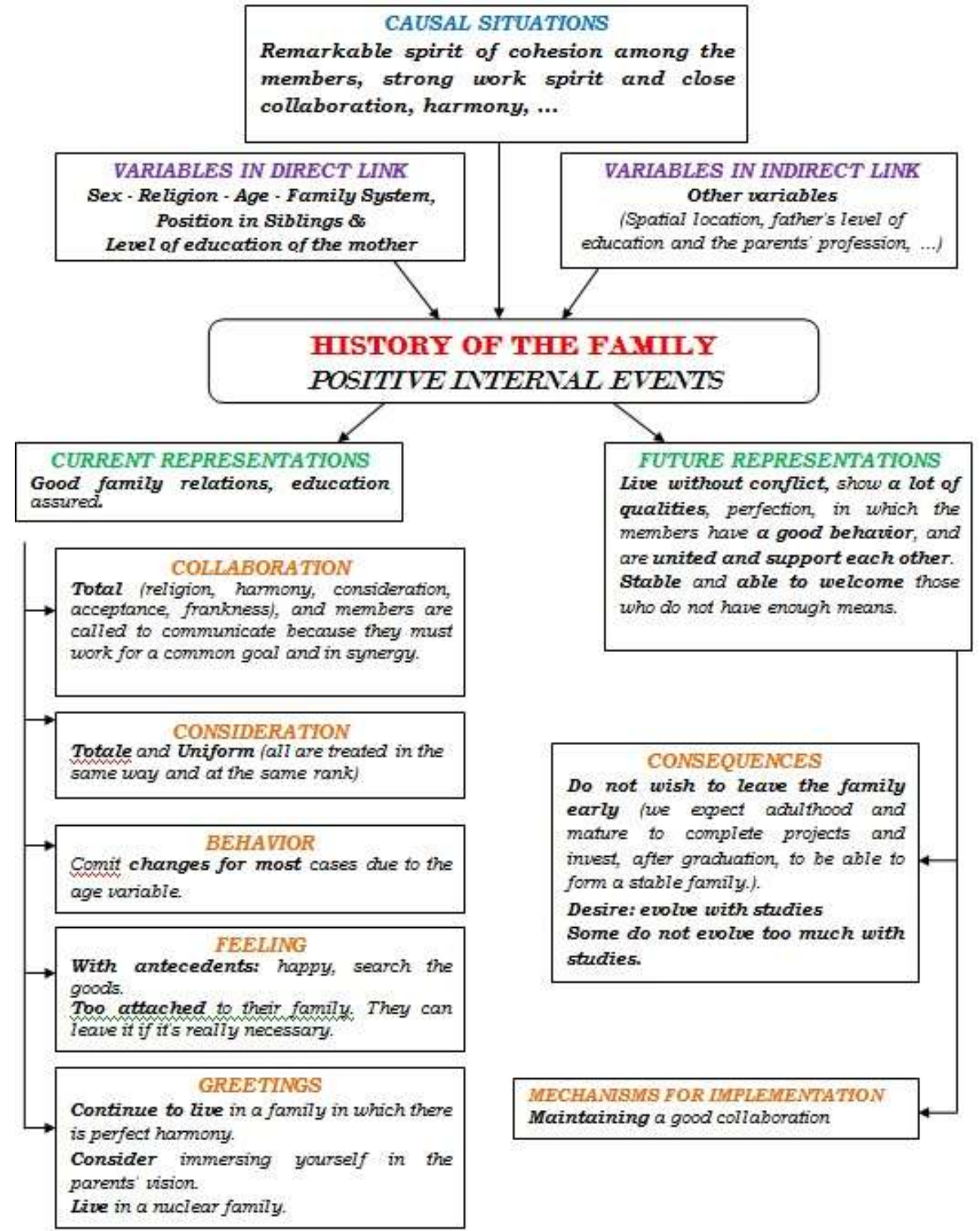

Figure 1: Model profile of the representation of adolescents in a situation of Positive Internal Events (IPE)

Volume 6 Issue 12, December 2017 www.ijsr.net

Licensed Under Creative Commons Attribution CC BY 
International Journal of Science and Research (IJSR)

ISSN (Online): 2319-7064

Index Copernicus Value (2016): 79.57 | Impact Factor (2015): 6.391

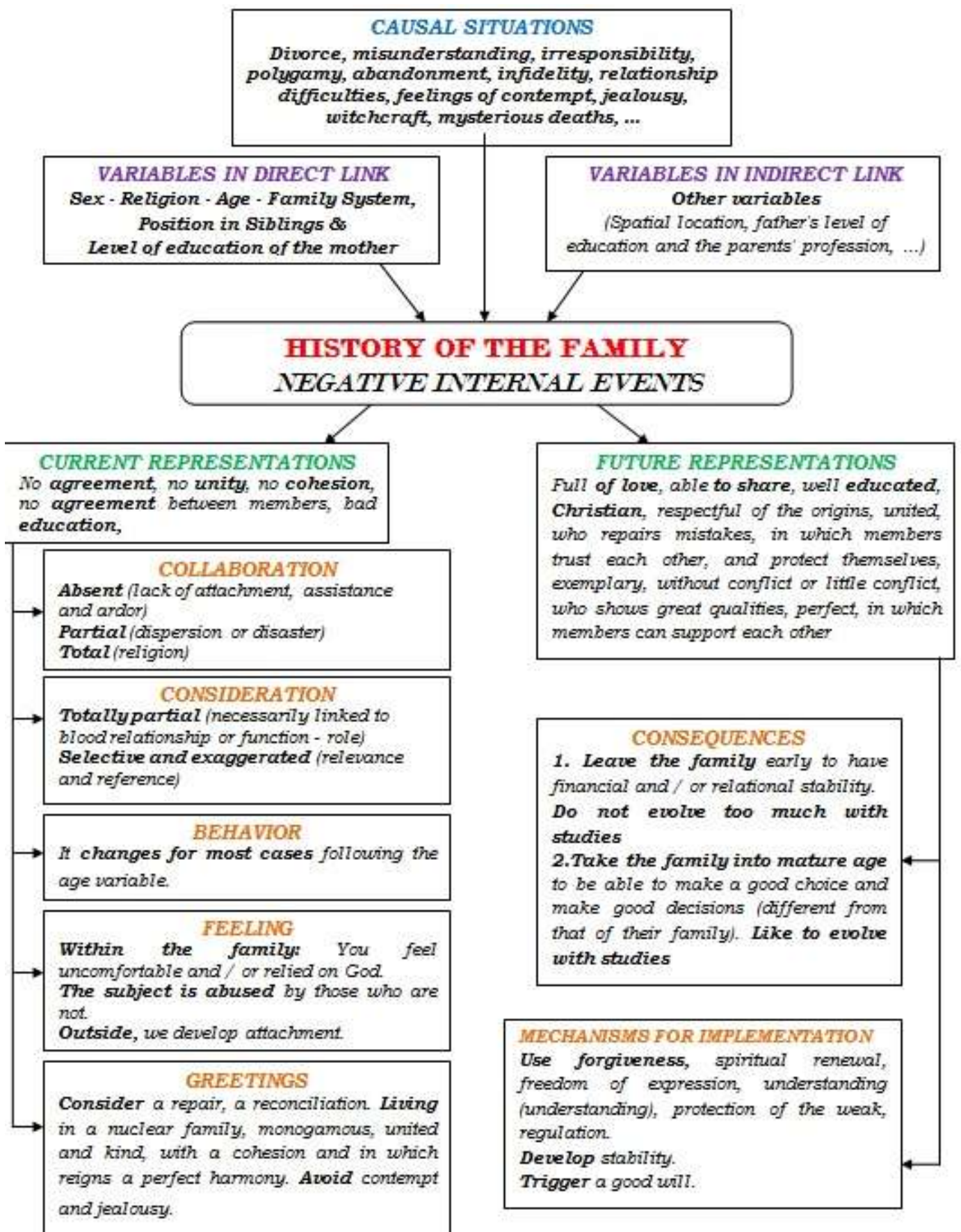

Figure 2: Model profile of the representation of adolescents in a situation of Internal Negative Events (EIN)

Volume 6 Issue 12, December 2017

www.ijsr.net

Licensed Under Creative Commons Attribution CC BY 
International Journal of Science and Research (IJSR)

ISSN (Online): 2319-7064

Index Copernicus Value (2016): 79.57 | Impact Factor (2015): 6.391

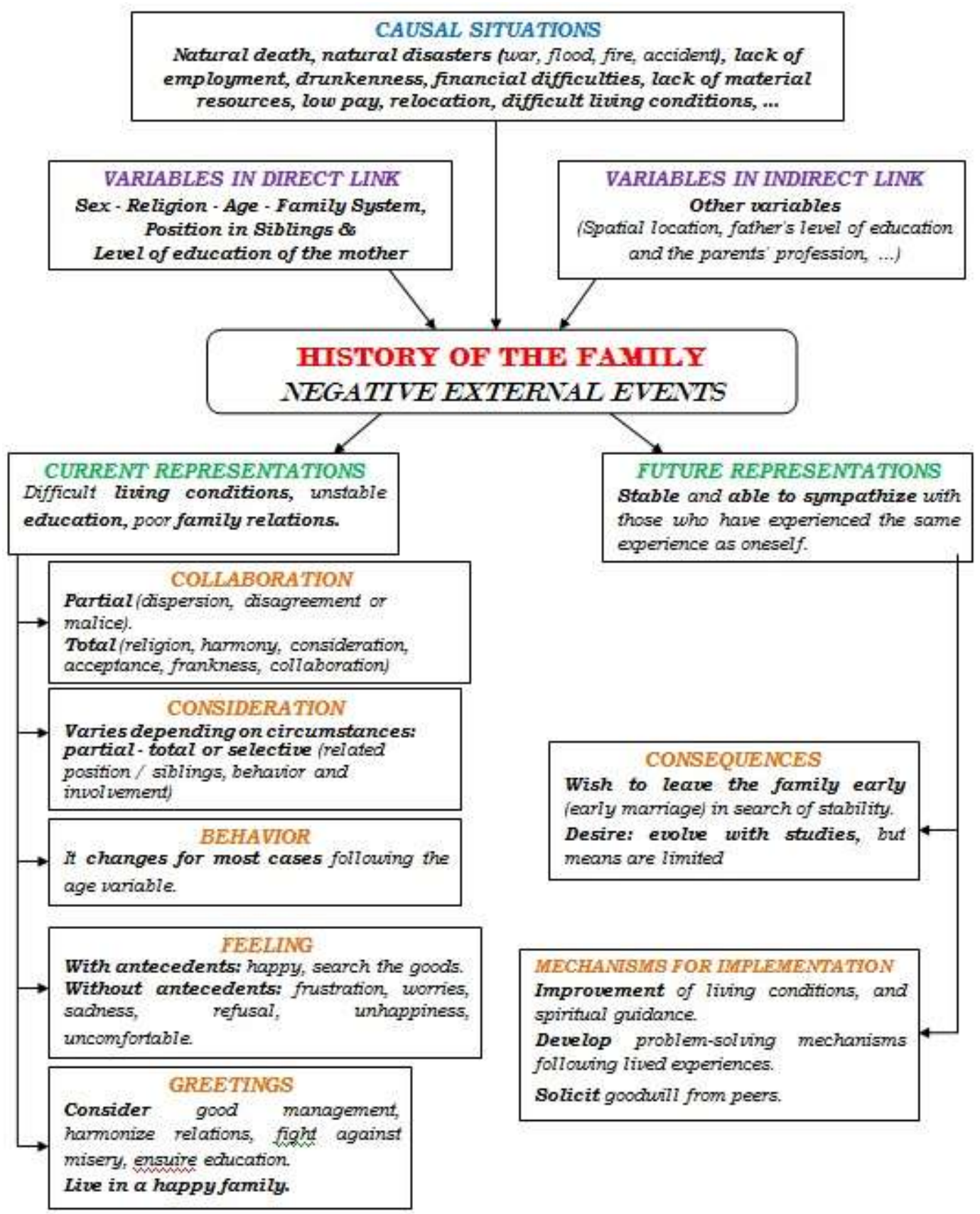

Figure 3: Model profile of the representation of adolescents in a Positive External Events (EEN) situation

Volume 6 Issue 12, December 2017

www.ijsr.net

Licensed Under Creative Commons Attribution CC BY 
International Journal of Science and Research (IJSR)

ISSN (Online): 2319-7064

Index Copernicus Value (2016): 79.57 | Impact Factor (2015): 6.391

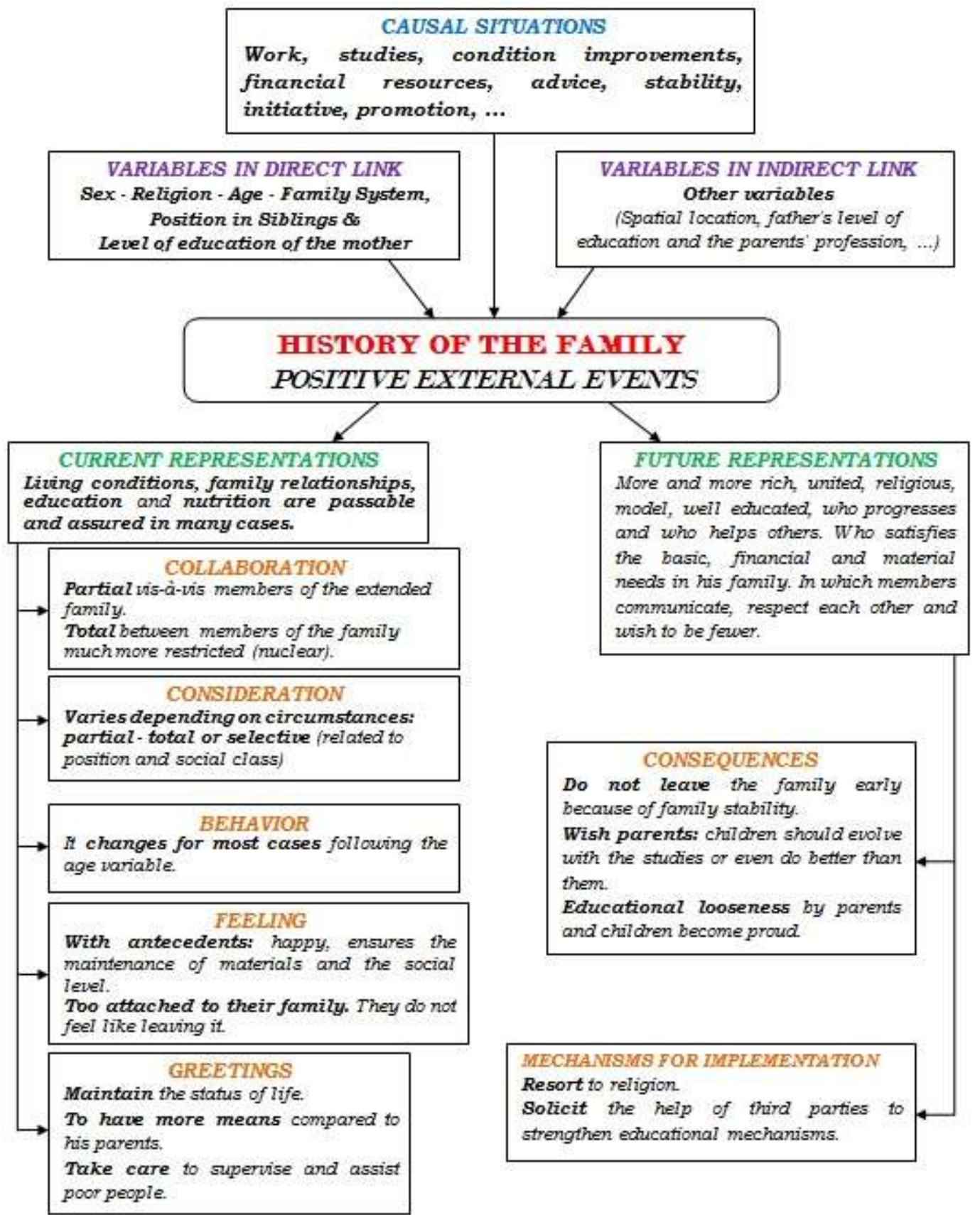

Figure 4: Model profile of the representation of adolescents in a situation of External Negative Events (EEP)

\section{Conclusion}

At the end of this exploratory study whose main purpose was on the one hand to sketch the different typical profiles of the Congolese family lushoise starting from narratives or speeches of family life, and on the other hand, to determine the element able to typologize this representation. It focused on the speeches of 70 adolescents who took an active part in this survey in the city of Lubumbashi, with 35 girls and 35 boys, whose average age is 15 years.

We arrive at the following results:

1. Notwithstanding the different age groups, the discourses produced were found to be coherent by thematic analysis.
2. The central element in typologizing adolescents' representations of their families is family history or the story of family life.

3. Starting from the discourses on the family, we distinguish four typical profiles which are presented in this way:

- Positive Internal Events (EIP);

- Internal Negative Events (EIN);

- External Positive Events (EEP);

- External Negative Events (EEN).

4. Girls tell each other more internally when talking about their families, while boys tell each other more externally.

Note however, that after this study, some gray areas remain. Hence, the fundamental questions that emerge and

\title{
Volume 6 Issue 12, December 2017
}

\author{
www.ijsr.net
}

Licensed Under Creative Commons Attribution CC BY 


\section{International Journal of Science and Research (IJSR) \\ ISSN (Online): 2319-7064}

Index Copernicus Value (2016): 79.57 | Impact Factor (2015): 6.391

that require further study in the rest of our doctoral research are the following: whether the origin of a speech alone explains all the representation that adolescents have about their families. If this is not the case, what are the other variables that come into play. It will also be a question of dismantling the relationship that exists between the representation made from the speech and the emergence of an emotional disorder. At the end of the doctoral research, and through these three separate studies, we will be able to:

1. Validate our modeling of the different typical profiles of the family: will the extension of the questionnaire to other young people allow us to categorize the speeches on the same schema;

2. Link the frequency of emotional disorders and family representations.

3. Determine the salient narrative elements in the speeches of depressed and anxious adolescents.

4. Determine the paradigm of emergence of depression and anxiety among young people, based on typical profiles of family representation.

\section{References}

[1] Ardilly, P. (1994). Polling techniques, Paris, Technip Publishing.

[2] Bizige, C. (2012). Sexual identity from a physical and psychological point of view man and woman. Chemchem, 12, 23-39. Lubumbashi: Editions Don Bosco.

[3] Boulard, A. (2012). Depressive mood in adolescents: statistics and narrativity. University of Liège, unpublished thesis.

[4] Castillo, M.-C., Lannoy, V., Seznec, J.-C., Januel, D. \& Petitjean, F., (2008). Study of social representations of schizophrenia in the general population and in a population of schizophrenic patients. Psychiatric evolution, 73, 615-628. doi: 10.1016 / j.evopsy.2007.06.006

[5] Delage, M. (2008). Family resilience Paris: Odile Jacob.

[6] Duret, I. \& Lefebvre, A. (1997). Seeking real family, at any cost. History of a shameful filiation. Cahiers de psychologie clinique, 9, 55-69. Brussels: De Boeck \& Larcier s.a. ISBN 2-8041-2649-8.

[7] Erikson, E. (1968). Identity, youth and crisis. New York: Freeman.

[8] Legras, B. \& Kohler, F. (2007). Elements of statistics for use by students of medicine and biology. Course and exercises corrected, 2nd edition, Ellipses Paris, "PCEM" collection. ISBN 978-2729-829711.

[9] Ferréol, G., Cauche, P., Duprez, J.-M., Gadrey, N. \& Simon, M. (Eds). (1991). Dictionary of Sociology (3rd ed.): Social representations. Paris: Armand Colin.

[10] Mannoni, P. (2012). Social representations (6th ed.) Paris: P.U.F.

[11] Moscovici, S. (1984). Social Psychology. Paris: P.U.F.

[12] Pauzé, R., Déry, M., Yergeau, E., \& Touchette, L. (2005). Diversity of profiles clinics of the families of children with behavior in school. New research notebooks in Education, 8, No. 2, 27-36. Québec: doi 10.7202 / 1017526ar

[13] Rassial, J-J. (2009). The Adolescent and the psychoanalyst. Paris: Small Payot Library.

[14]Ricœur, P., (1983). Time and Story: Volume I, Intrigue and Historical Narrative. Paris: The Threshold.

[15] Somers, M. (1994). The narrative constitution of identity: A relational and network approach. Theory and Society, 23, 605-649.

[16] Sylvie, P. (2011). The evolution of the family. The Journal of Psychologists, 9/2011 (No. 292), 20-20. doi: 10.3917 / jdp.292.0020

\section{Appendix 1. Service Guide}

\section{Order}

I kindly ask you to participate in this survey, which is designed primarily for scientific purposes and which deals with the representation of the family by young Congolese. I grant you the freedom to develop your ideas as you see fit by answering the questions below. At the 14th question, I will provide you with the necessary information in relation to the different types of family listed. For this purpose, I guarantee you anonymity and I thank you in advance!

1. Explain to me what makes your family become what it is today? (Do not forget to refer to the positive and negative facts).

2. If you are allowed to change something to your family's current situation, what would you change?

3. What type of ideal family would you like to belong to? Why?

4. When you grow up, what kind of family will you like to train? Why?

5. What do you blame your family for and what do you propose as a solution to this?

6. What difference can you make between your current family and the one you will form?

7. Tell us about your family (Do not forget to refer to the composition of the different members).

8. How does the collaboration between the parents and the children you are?

9. How does the consideration of your parents and siblings manifest themselves to you?

10. At what age can you decide to go live in another family? Why?

11. Have you ever changed your behavior as a result of the attitudes displayed by your parents or siblings? Explain.

12. Are you really considered by your family? If yes, show it, otherwise, tell me why.

13. How will you feel if you are asked to leave your family to live in another family and what would be the disadvantages?

14. Among the family types below, choose the type of family to which you belong and to which you would like to belong: nuclear, divorced, single parent, recomposed, adoptive, under guardianship, polygamous,... 